\title{
Solar Radiation Incident on Mars and the Outer Planets: Latitudinal, Seasonal, and Atmospheric Effects
}

\author{
JoEL S'. IAEVINE \\ Atmospheric Environmental Sciences Division, NASA Langley Research Center, \\ Hampton, Virginia 23665 \\ A.VI) \\ Davin R. Kragmer ani Willian R. Kuhy \\ Department of Atmospheric and Oceanic Science, The University of Michigan, \\ Ann Arbor, Michigan 4810 ,
}

lieceived August 6, 1976 ; revised December :3, 1976

\begin{abstract}
Calculations of the daily solar radiation incident at the tops of the atmospheres of Mars and the outer planets and its variability with latitude and season are presented in a series of figures and tables similar to those for Farth in The Smithsonian Meteorological Tables. The changes in the latitudinal and seasonal distributions of daily surface insolation during the great Martian dust storm of 1971 (when Martian atmospheric optical depth increased from about $r=0.1$ to 2.0) were significant and dramatically illustrate the effect of atmospheric aerosols on surface insolation; i.e., the mean annual daily insolation at the poles decreased by more than a factor of 100 as $\tau$ increased from 0.1 to 2.0 .
\end{abstract}

\section{INTROIDUCTION}

The distribution of incident solar radiation and its variability with latitude, season, and atmospherie turbidity is of prime inportance in studies of the Earth's radiation and energy budget, climatology, weather, and global circulation and dynamies. For this reason, the figures and tables of the daily solar radiation incident at the top of the Earth's atmosphere and at the Farth's surface as a function of latitude, season, and atmospheric turbidity given in The Smithsomian Meteorological Tables and soveral other atmospheric science references and textbooks are an important and useful research aid. To the best of our knowledge, similar calculations for the other planets have not been published. With this in mind, we present calculations of the daily solar radiation incident on the other rapidly rotating planets in the solar system- Mars, Jupiter, Saturn, Lranus and Neptune--as a function of latitude and season. In addition, we have investigated the effect of increased global atmospheric turbidity (resulting from wind-blown dust during the great Martian dust storm of 1971) on the seasonal and latitudinal distributions of insolation at the Martian surface. Wo present calculations of Martian surface insolation for atmospheric optical thickness, $\tau=0.1,0.35$, and 2.0 . As expected, the distribution of Martian surface insolation was greatly altered by the increase of atmospheric acrosols; i.c., the mean annual daily insolation at the Martian poles decreased by more than a factor of 100 as $\tau$ increased from 0.1 to 2.0 during the great dust storm of 1971.

The results of our calculations are presented in a series of figures and in two 
tables. In the figures, the incident solar radiation is given in contours of calories per square centimeter/planetary day as a function of planetary latitude and season. Following the convention in The Smithsonian Meteorological Tables, the planet's season is represented by the heliocentric longitude, which is given on the abscissa. A heliocentric longitude of $0^{\circ}$ corresponds to the Northern Hemisphere vernal equinox, $90^{\circ}$ corresponds to the Northern Hemisphere summer solstice, $180^{\circ}$ corresponds to the Northern Hemisphere autumnal equinox, and $270^{\circ}$ corresponds to the Northern Hemisphere winter solstice. The declination of the Sun is represented by a dashed line.

The mean annual daily solar radiation incident at the top of the Martian atmosphere and reaching the Martian surface as a function of latitude for various turbidity conditions is given in Table II. The mean annual daily solar radiation incident at the tops of the atmospheres of Jupiter, Saturn, Uranus, and Neptune as a function of latitude is given in Table III. Since the mean annual daily solar radiation values given in Tables II and III are symmetric with respect to the planet's equator, a value at a given latitude applies to either hemisphere.

\section{CALCULATION OF SOLAR RADIATION INCIDENT ON A PLANETARY ATMOSPHERE AND SURFACE}

The amount of solar radiation incident at the top of a planetary atmosphere, $I_{0}$ (cal $\mathrm{cm}^{-2} \mathrm{~min}^{-1}$ ) can be expressed as

$$
I_{0}=\left[S_{0} /\left(r / a_{e}\right)^{2}\right] \cos z,
$$

where $S_{0}$ is the solar constant at the mean Sun-Earth distance of $1 \mathrm{AU}$, taken to be $1.94 \mathrm{cal} \mathrm{cm}^{-2} \mathrm{~min}^{-1}, z$ is the zenith angle of the incident solar radiation, $r$ is the instantaneous Sun-planet distance, and $a_{\mathrm{e}}$ is the semimajor axis of the Earth's orbit ( $1 \mathrm{AU})$. The instantaneous position of the planet in its orbit can be expressed as the angular distance, $\theta$ from perihelion, and is related to the orbital elements by

$$
r=a\left(1-e^{2}\right) /(1+e \cos \theta),
$$

where $a$ and $e$ are the planet's semimajor axis and eccentricity, respectively. The position of perihelion is given by Melbourne et al. (1968).

The zenith angle of the incident solar radiation, $z$, can be expressed as

$\cos z=\sin \phi \sin \delta+\cos \phi \cos \delta \cos h$,

where $\phi$ is the planetary latitude, $\delta$ is the solar declination, and $h$ is the local hour angle of the Sun.

For a rapidly rotating planet, (1) can be integrated to yield the amount of solar radiation incident at the top of a planetary atmosphere over the planet's day, $\tilde{I}_{0}$ [cal $\mathrm{cm}^{-2}$ (planetary day) $\left.{ }^{-1}\right]$, and is given by

$$
\begin{array}{r}
\tilde{I}_{0}=\left(P S_{0} / \pi\right)\left(a_{\mathrm{e}} / r\right)^{2}\left[\cos \delta \cos \phi \sin h_{0}\right. \\
\left.+h_{0} \sin \delta \sin \phi\right],
\end{array}
$$

where $P$ is the planet's rotation period in minutes, and $h_{0}$ is the local hour angle at sunset which can be determined from (3). The solar declination is given by

$$
\sin \delta=\sin \epsilon \sin \lambda,
$$

where $\epsilon$ is the obliquity, the inclination of equator to orbit (the angle between the orbital and rotational planes), and $\lambda$ is the planetary longitude measured from the intersection of these planes. $\epsilon$ is the complement of the angle corresponding to the latitude of the North Pole of the planet relative to the planet's orbit and is found from standard spherical trigonometric relationships and the right ascension and declination of the planetary pole and orbital data given by Melbourne et al. (1968). $\lambda$ determines the locations of the solstices and equinoxes on the planetary orbit. Planetary data are given in Table I.

To calculate the solar radiation incident, on a planctary surface over the planet's day $\widetilde{I}_{\mathrm{s}}\left[\mathrm{cal} \mathrm{cm}^{-2}\right.$ (planetary day) $\left.{ }^{-1}\right]$ as a 
TABLE I

Planetary 1)ata

\begin{tabular}{lcccccc}
\hline & $\begin{array}{c}\text { Semimajor } \\
\text { axis } \\
\text { (AU) }\end{array}$ & Eccentricity & $\begin{array}{c}\text { Orbital } \\
\text { period } \\
\text { (tropical } \\
\text { years) }\end{array}$ & $\begin{array}{c}\text { Argument } \\
\text { of } \\
\text { Perihelion } \\
\text { (deg) }\end{array}$ & $\begin{array}{c}\text { Obliquity } \\
\text { (deg) }\end{array}$ & $\begin{array}{c}\text { Rotation } \\
\text { period } \\
\text { (hr) }\end{array}$ \\
\hline Mars & 1.524 & 0.093 & 1.88 & 248 & 24.94 & 24.62 \\
Jupiter & 5.203 & 0.048 & 11.86 & 58 & 3.07 & 9.84 \\
Saturn & 9.539 & 0.056 & 29.46 & 279 & 26.74 & 10.27 \\
Uranus & 19.18 & 0.047 & 84.01 & 3 & 97.93 & 10.82 \\
Neptune & 30.06 & 0.009 & 164.79 & 6 & 28.80 & 15.8 \\
\hline
\end{tabular}

${ }^{a}$ From Mars Engineering Model (1974) and Newburn and Gulkis (1973).

${ }^{b}$ Referenced to the vernal equinox at solar longitude $=0^{\circ}$.

function of latitude, season, and atmospheric turbidity, we assume that the incoming solar radiation is attenuated by a mean atmospheric optical depth, $\tau$, such that

$$
\begin{aligned}
& \tilde{I}_{\mathrm{s}}=\left(P S_{0} / \pi\right)\left(a_{\mathrm{v}} / r\right)^{2} \\
& \times \int_{0}^{h_{0}}(\cos h \cos \delta \cos \phi+\sin \delta \sin \phi) \\
& \quad \times \exp [-\tau /(\cos h \cos \delta \cos \phi \\
& \quad+\sin \delta \sin \phi)](h .
\end{aligned}
$$

This equation was solved numerically by a modified Simpson integration.

\section{DISCUSSION OF CALCULATIONS}

\section{Mars}

As a result of the gravitational perturbations of the Sun and the other planets, the orbital eccentricity and obliquity of Mars have experienced substantial cyclical variations over its history. These changes in ecentricity and obliquity have caused corresponding variations in the intensity and planetary-wide distribution of solar radiation incident on Mars. Over its history, the orbital ecentricity of Mars has varied from 0.004 to 0.141 and its obliquity has varied from 14.9 to $35.5^{\circ}$ (Murray el al., 1973; Ward, 1974). For the calculations presented in this paper we have adopted the present values of eceentricity and obliquity of 0.093 and $24.94^{\circ}$, respectively. Figure 1 shows the distribution of solar radiation incident at the top of the atmosphere of Mars. The maximum radiation occurs over the southern and northern poles. By comparison, the Earth receives 1100 and $1000 \mathrm{cal} \mathrm{cm}^{-2} \mathrm{day}^{-1}$ at the poles at the southern and northern summer solstices, respectively. Maxima in the incident solar radiation over the poles during the solstices occur because of the continuous daylight which overeompensates for the large solar zenith angle. Such a situation occurs whenever the obliquity, $\epsilon \widetilde{>} 18^{\circ}$, which is true not only for Mars and the Earth, but also for Saturn, Uranus, and Neptune (sce Table I).

Figure 2 shows the distribution of solar radiation at the surface of Mars for clear sky conditions $(\tau=0.1)$. In general, this distribution follows the distribution at the top of the atmosphere, except for magnitude, which is decreased somewhat because of clear sky absorption and scattering. A significant hemispheric seasonal asymmetry exists in that there is considerably more insolation over the southern polar regions than the northern polar regions during local summer solstice. Since the southern winter scason occurs at aphelion, it is colder and of longer duration than the northern winter season. This results in 


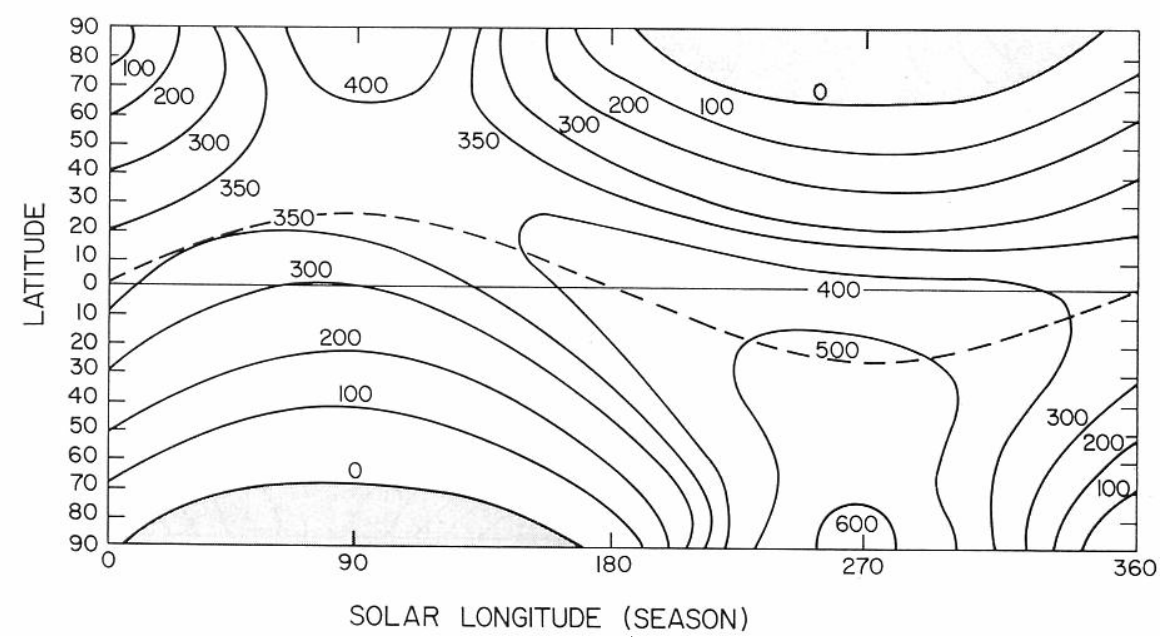

FIG. 1. Solar radiation incident at the top of the Martian atmosphere [in cal $\mathrm{cm}^{-2}$ (planetary (ay) $\left.)^{-1}\right]$.

a more extensive southern polar cap. The rapid near-compiete melting of the southern polar cap results from the hotter southern summer. The northern polar cap remnant is a permanent surface feature resulting from the cooler summer in the Northern Hemisphere.

The effects of various concentrations of atmospheric dust on the insolation distribution are shown in Figs. 3 and 4 . Figure 3 shows the distribution at the Martian surface for $\tau=0.35$. The point of maxi- mum insolation has moved equatorward, since the larger zenith angle and thus the larger optical depth exerts a stronger effect than the longer daylight hours.

Figure 4 shows the surface insolation at the height of the great Martian dust storm corresponding to an optical depth, $\tau=2$ (Masursky et al., 1972). The insolation distribution closely parallels the seasonal march of the Sun, with maximum insolation in the tropies and only small amounts of solar radiation reaching the polar regions.

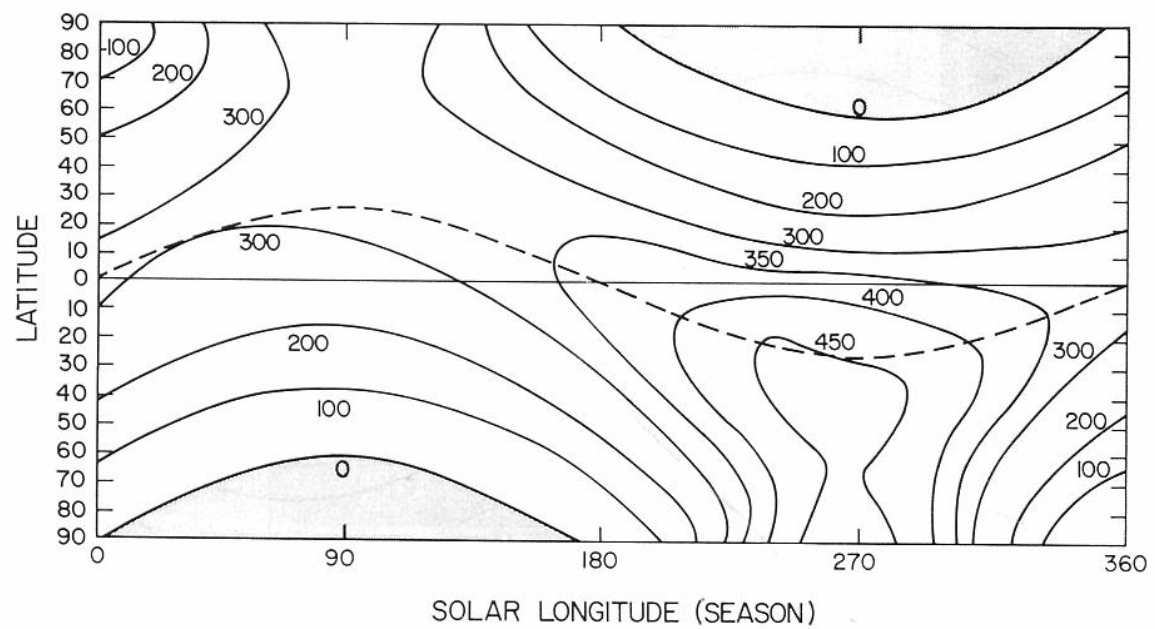

FIG. 2. Solar radiation incident at the Martian surface $(\tau=0.10)$ [in $\mathrm{cal} \mathrm{cm}^{-2}$ (planetary day) $\left.{ }^{-1}\right]$. 


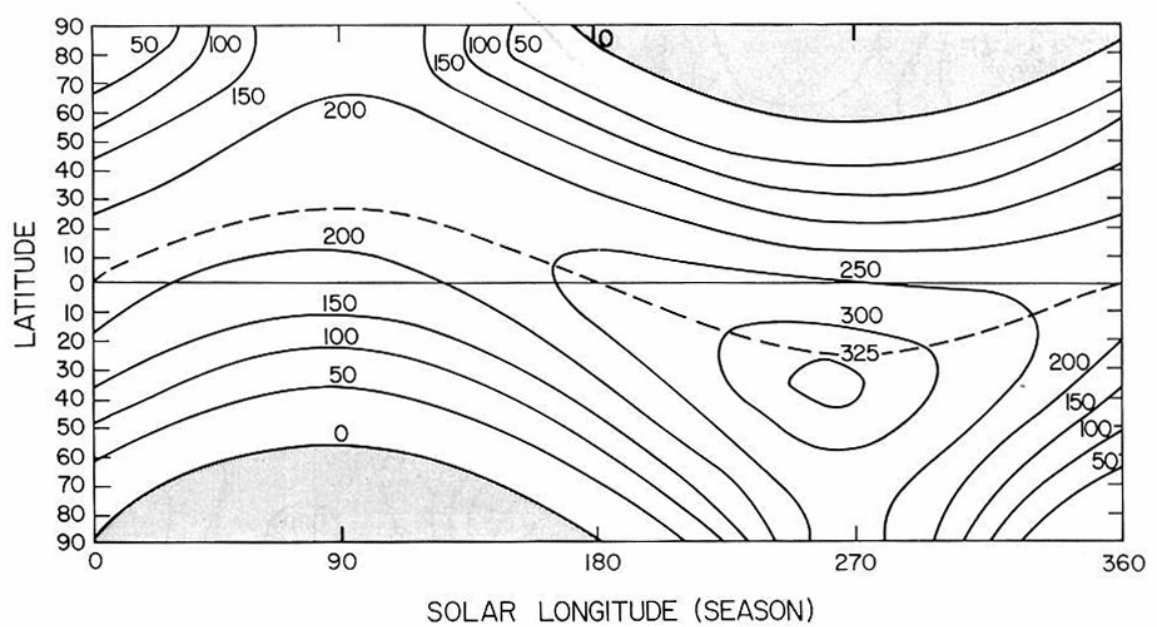

Fra. 3. Solar radiation incident at the Martian surface $(\tau=0.35)\left[\right.$ in cal $\mathrm{cm}^{-3}$ (planetary day) $\left.{ }^{-1}\right]$.

For example, in the polar latitudes during the Southern Hemisphere summer, the insolation is only about $5 \%$ of the clear sky values.

The moan annual daily solar radiation incident at the top of the Martian atmosphere and reaching the Martian surface as a function of latitude for the various atmospheric turbidity conditions in Figs. 1 to 4 is summarized in Table II.

It is interesting to note that the great Martian dust storm of 1971 began at about the latitude and about the time of year of maximum solar insolation (see Figs. 2 to 4). In reviewing the great Martian dust storm of 1971, as well as previous planetwide dust storms, Gierasch (1974) points out that indeed certain geographical regions are favored for the development of these storms. The storms usually develop between 20 and $40^{\circ} \mathrm{S}$ latitude near or slightly before the Southern Hemisphere summer solstice. Large amounts of solar radiation could have been absorbed by relatively

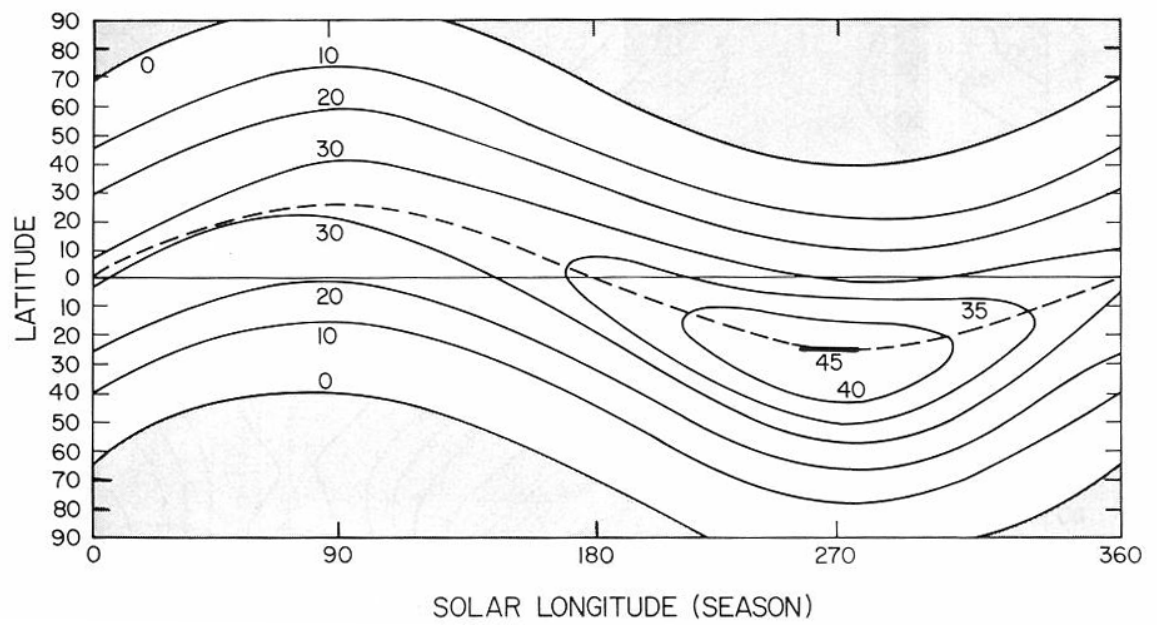

Fia. 4. Solar radiation incident at the Martian surface $(\tau=2.0)$ [in cal $\mathrm{cm}^{2}$ (planetary day $)^{-1}$ ]. 
TABLF II

Mean Annual Daily Solar Radiation Incident at Top of the Atmosphere and at the Surface of Mars ${ }^{a}$

\begin{tabular}{rllcc}
\hline Lat. & $\begin{array}{c}\text { Top of } \\
\text { atmosphere }\end{array}$ & $\begin{array}{c}\text { Surface } \\
(\tau=0.1)\end{array}$ & $\begin{array}{c}\text { Surface } \\
(\tau=0.35)\end{array}$ & $\begin{array}{c}\text { Surface } \\
(\tau=2.0)\end{array}$ \\
\hline 8.5 & $0.167 \times 10^{3}$ & $0.118 \times 10^{3}$ & $0.559 \times 10^{2}$ & 0.877 \\
80 & $0.170 \times 10^{3}$ & $0.121 \times 10^{3}$ & $0.599 \times 10^{2}$ & $0.143 \times 10^{1}$ \\
75 & $0.176 \times 10^{3}$ & $0.128 \times 10^{3}$ & $0.666 \times 10^{2}$ & $0.232 \times 10^{1}$ \\
70 & $0.185 \times 10^{3}$ & $0.137 \times 10^{3}$ & $0.759 \times 10^{2}$ & $0.352 \times 10^{1}$ \\
65 & $0.198 \times 10^{3}$ & $0.150 \times 10^{3}$ & $0.871 \times 10^{2}$ & $0.501 \times 10^{1}$ \\
60 & $0.217 \times 10^{3}$ & $0.167 \times 10^{3}$ & $0.997 \times 10^{2}$ & $0.677 \times 10^{1}$ \\
55 & $0.238 \times 10^{3}$ & $0.186 \times 10^{3}$ & $0.114 \times 10^{3}$ & $0.874 \times 10^{1}$ \\
50 & $0.259 \times 10^{3}$ & $0.206 \times 10^{3}$ & $0.129 \times 10^{3}$ & $0.109 \times 10^{2}$ \\
45 & $0.279 \times 10^{3}$ & $0.225 \times 10^{3}$ & $0.144 \times 10^{3}$ & $0.132 \times 10^{2}$ \\
40 & $0.297 \times 10^{3}$ & $0.243 \times 10^{3}$ & $0.158 \times 10^{3}$ & $0.156 \times 10^{2}$ \\
35 & $0.315 \times 10^{3}$ & $0.260 \times 10^{3}$ & $0.172 \times 10^{3}$ & $0.180 \times 10^{2}$ \\
30 & $0.330 \times 10^{3}$ & $0.275 \times 10^{3}$ & $0.185 \times 10^{3}$ & $0.204 \times 10^{2}$ \\
25 & $0.344 \times 10^{3}$ & $0.288 \times 10^{3}$ & $0.196 \times 10^{3}$ & $0.227 \times 10^{2}$ \\
20 & $0.355 \times 10^{3}$ & $0.299 \times 10^{3}$ & $0.206 \times 10^{3}$ & $0.247 \times 10^{2}$ \\
15 & $0.364 \times 10^{3}$ & $0.308 \times 10^{3}$ & $0.213 \times 10^{3}$ & $0.264 \times 10^{2}$ \\
10 & $0.370 \times 10^{3}$ & $0.314 \times 10^{3}$ & $0.219 \times 10^{3}$ & $0.277 \times 10^{2}$ \\
5 & $0.374 \times 10^{3}$ & $0.318 \times 10^{3}$ & $0.222 \times 10^{3}$ & $0.285 \times 10^{2}$ \\
0 & $0.375 \times 10^{3}$ & $0.319 \times 10^{3}$ & $0.223 \times 10^{3}$ & $0.288 \times 10^{2}$ \\
\hline
\end{tabular}

${ }^{a}$ For $\tau=0.1,0.35$. and 2.0 [in cal $\mathrm{cm}^{-2}$ (Mars day) ${ }^{-1}$ ].

small amounts of wind-blown dust in the Martian atmosphere. According to the Mars dust storm models of Gierasch and Goody (1973), Leovy et al., (1973), Golitsyn (1973), and Hess (1973), this process may have triggered the planet-wide dust storm that followed.

Wind-blown dust in the Martian atmosphere can absorb significant amounts of solar radiation, which in turn can alter the temperature, thermal structure, and $\mathrm{dy}$ namics of the Martian lower atmosphere. Gierasch and Goody (1972) concluded that a high-temperature, near-isothermal atmosphere could result from the dust conditions during the 1971 dust storm. Their calculations indicate that the solar radiation absorbed by wind-blown dust was enough to increase the lower atmosphere temperature by $25^{\circ} \mathrm{K}$ day $^{-1}$. The Mariner 9 infrared spectrometer experiment (Hanel et al., 1972) and the radio occultation experiment (Kliore et al., 1972) show that the temperature of the atmosphere was raised about $50^{\circ} \mathrm{K}$ during the storm, and that the temperature profiles became almost isothermal.

\section{Jupiter}

The distribution of radiation incident on the Jovian atmosphere is shown in Fig. 5 and, because of the small obliquity, is nearly symmetric with respect to the equator. At the equator the incident solar radiation varies between 12 and 1.5 cal $\mathrm{cm}^{-2}$ (Jovian day) ${ }^{-1}$ over the year. Perihelion occurs near the Northern Hemisphere summer solstice, resulting in an equatorial maximum in solar radiation at this time of the year. The actual latitudinal variation of absorbed solar radiation is probably much smaller than the variation of incident radiation shown in Fig. 5 since the low and midlatitudes contain the cloud zones which would reflect a significant amount of visible radiation. 


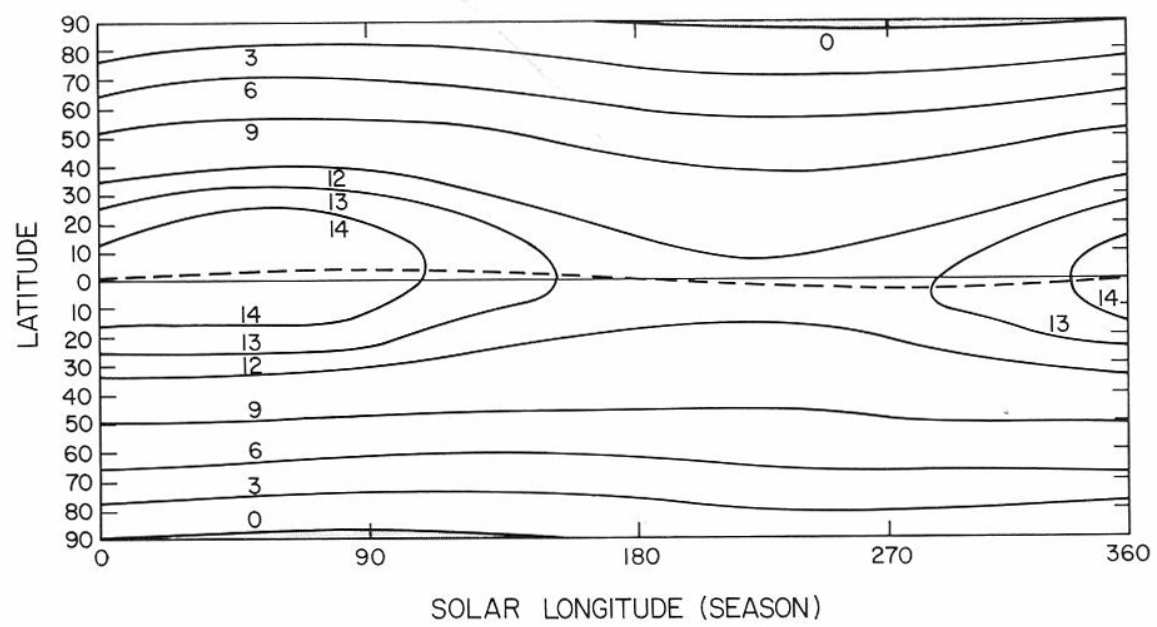

FIG. 5. Solar radiation incident at the top of the atmosphere of Jupiter [in cal $\mathrm{cm}^{-2}$ (planetary day) $\left.{ }^{-1}\right]$.

\section{Saturn}

The larger obliquity of Saturn results in maximum insolation at the poles, as shown in Fig. 6. Perihelion occurs at the Southern Hemisphere summer solstice, resulting in maximum solar radiation of about 6 cal $\mathrm{cm}^{-2}$ (Saturn day)-1. Because of the larger obliquity, the insolation pattern for Saturn is very different from that for Jupiter. Williams and Robinson (1973) have used this as one argument for internal heating as the primary cause of the similar dynamical effects on the two planets. The effect of solar radiation on the dynamies has yet to be investigated. The actual distribution of solar radiation incident at the top of the atmosphere of Saturn is eomplicated by the shadow effect of the ring system, which is not included in our calculations.

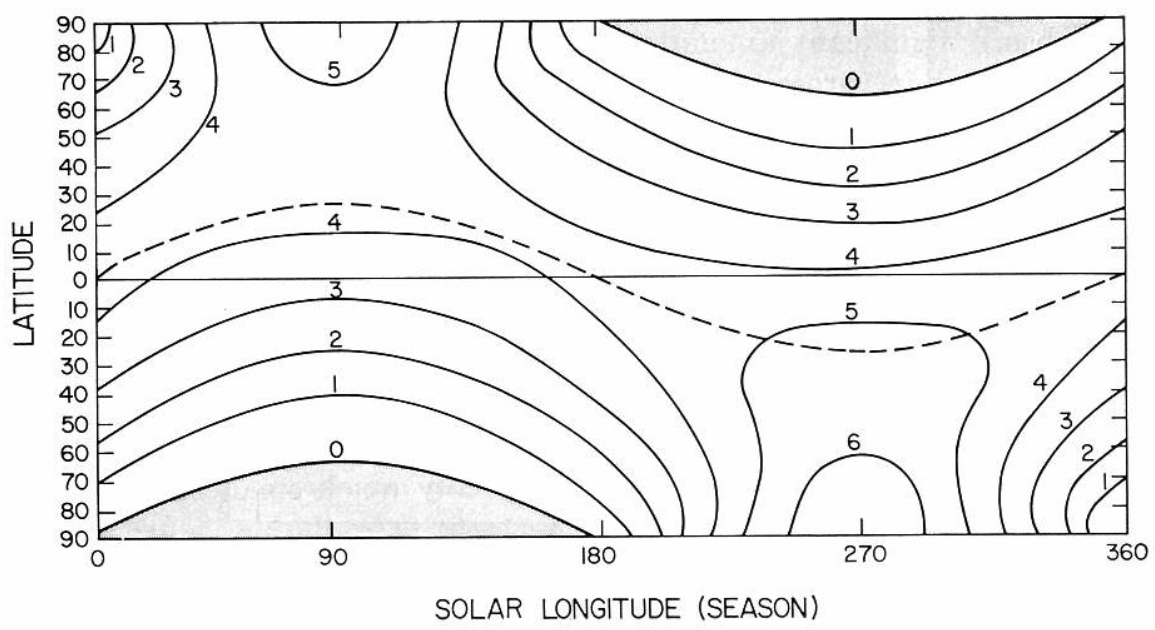

Fig. 6. Solar radiation incident at 1 op of the atmosphere of Saturn [in cal $\mathrm{mm}^{-2}$ (planetary day) $\left.{ }^{-1}\right]$. 


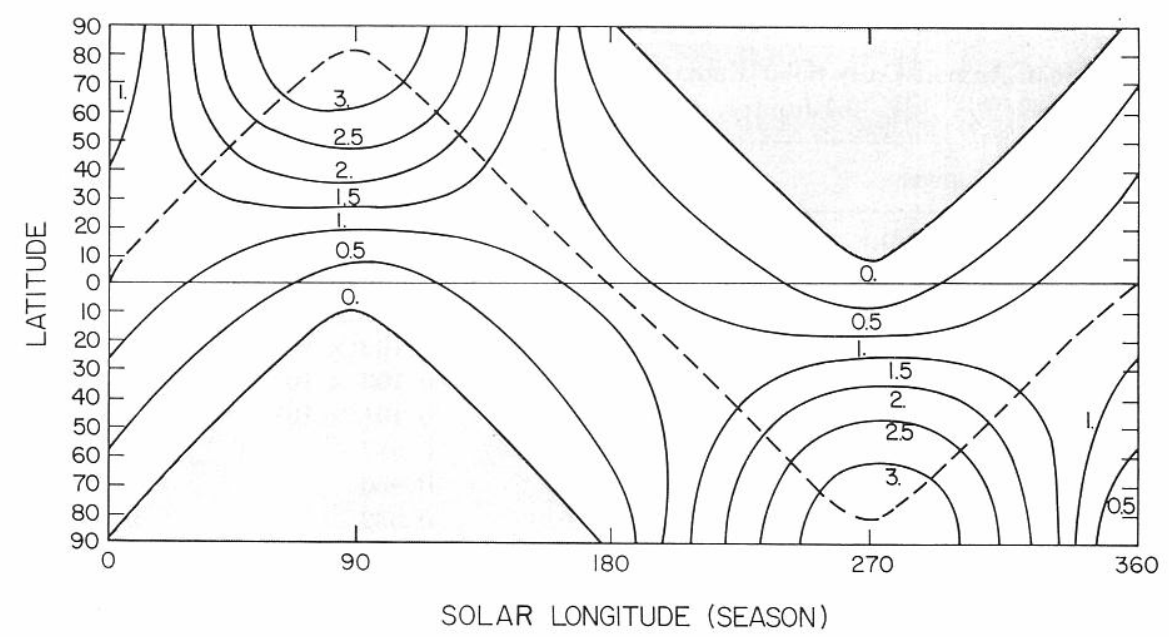

Fig. 7. Solar radiation incident at top of the atmosphere of Uranus [in cal $\mathrm{cm}^{-2}$ (planetary day) ${ }^{-1}$ ].

\section{Uranus}

The very large obliquity of Uranus (98) results in a bizarre distribution of solar radiation (Fig. 7). The position of the hemispheres is reversed with the Northern Hemisphere "below" the ecliptic and the Southern Hemisphere "above" the ecliptic. Maximum solar radiation is incident at the poles around the summer solstices, with values of about $3 \mathrm{cal} \mathrm{cm}^{-2}$ (Uranus day) ${ }^{-1}$; this situation will occur around 1985. For nearly half the Uranus year (approximately 42 Earth years), some parts of the planet are in perpetual darkness. Whether the small insolation received by the planet is important to the dynamics has yet to be determined, but if so, one would expect a circulation much different from the circulations of other rapidly rotating planets in the solar system. Temperature differences and the resulting condensation products between the light and dark sides as well

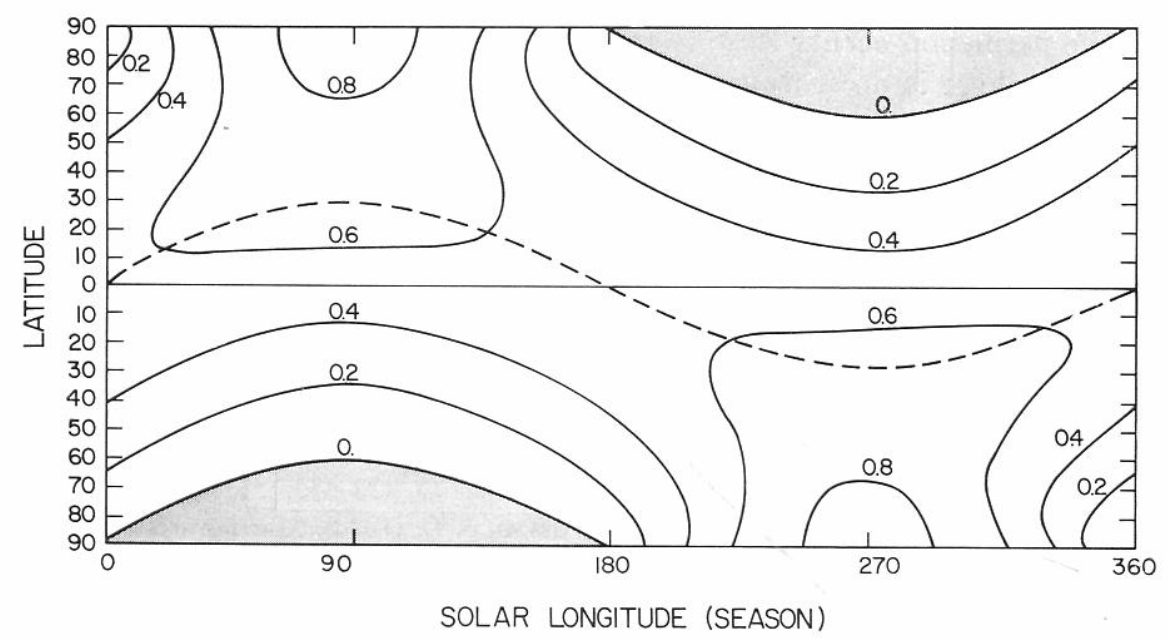

Fig. 8. Solar radiation incident at top of the atmosphere of Neptune [in $\mathrm{cal} \mathrm{cm}^{-2}$ (planetary (day) $)^{-1}$. 
TABLE III

Mean Annual Daily Solar Radiation Incident at the Tops of the Atmospheres of Jupiter, satum, I'anus and Neptune"

\begin{tabular}{cllll} 
Lat. & Jupiter & Saturn & Uranus & Neptune \\
\hline 85 & $0.128 \times 10^{1}$ & $0.191 \times 10^{1}$ & $0.108 \times 10^{1}$ & 0.279 \\
80 & $0.239 \times 10^{1}$ & $0.194 \times 10^{1}$ & $0.107 \times 10^{1}$ & 0.283 \\
75 & $0.352 \times 10^{1}$ & $0.200 \times 10^{1}$ & $0.106 \times 10^{1}$ & 0.289 \\
70 & $0.463 \times 10^{1}$ & $0.208 \times 10^{1}$ & $0.105 \times 10^{1}$ & 0.299 \\
6.5 & $0.571 \times 10^{1}$ & $0.219 \times 10^{1}$ & $0.103 \times 10^{1}$ & 0.311 \\
60 & $0.675 \times 10^{1}$ & $0.236 \times 10^{1}$ & $0.101 \times 10^{1}$ & 0.330 \\
55 & $0.774 \times 10^{1}$ & $0.256 \times 10^{1}$ & 0.987 & 0.355 \\
50 & $0.867 \times 10^{1}$ & $0.277 \times 10^{1}$ & 0.960 & $0.3 \times 1$ \\
45 & $0.954 \times 10^{1}$ & $0.297 \times 10^{1}$ & 0.932 & 0.408 \\
40 & $0.103 \times 10^{2}$ & $0.316 \times 10^{1}$ & 0.901 & 0.433 \\
35 & $0.110 \times 10^{2}$ & $0.334 \times 10^{1}$ & 0.871 & 0.456 \\
30 & $0.117 \times 10^{2}$ & $0.350 \times 10^{1}$ & 0.839 & 0.477 \\
25 & $0.122 \times 10^{2}$ & $0.364 \times 10^{1}$ & 0.808 & 0.496 \\
20 & $0.127 \times 10^{2}$ & $0.375 \times 10^{1}$ & 0.778 & 0.511 \\
15 & $0.130 \times 10^{2}$ & $0.3 \times 4 \times 10^{1}$ & 0.752 & 0.523 \\
10 & $0.133 \times 10^{2}$ & $0.391 \times 10^{1}$ & 0.730 & 0.532 \\
5 & $0.134 \times 10^{2}$ & $0.395 \times 10^{1}$ & 0.717 & 0.537 \\
0 & $0.135 \times 10^{2}$ & $0.396 \times 10^{1}$ & 0.714 & 0.539 \\
\hline
\end{tabular}

a In eal $\mathrm{cm}^{-2}$ (planetary day ${ }^{-1}$ ).

as photochemical reactions rould cause changes in atmospheric composition.

\section{Neptune}

For completeness, the solar radiation incident on Neptune is given in Fig. 8 . The maximum solar radiation falls on the polar regions. Since perihelion occurs close to the vernal equinox, there is no seasonal asymmetry in the distribution of incident solar flux.

The mean annual daily solar radiation incident at the tops of the atmospheres of Jupiter, Saturn, Uranus, and Neptune as a function of latitude is summarized in Table III.

The latitudinal gradient and the scasonal variation of incoming solar radiation constitute a driving force in determining the circulation and dynamics of the Earth's atmosphere. The latitudinal variation of the mean annual daily solar radiation received at the Earth's surface is important in determining elimate and woather pat- terns. We believe the calculations presented in this paper should help in studies of the radiation and energy budget, circulation, dynamies, climatology, and weather of Mars and the outer planets.

\section{REFLRENCWS}

(intusch, P. J. (1974). Martian dust storms. Rev. Geophys. Space Phys. 12, 730-734.

Giknsch, P. J., ani Goody, R. M. (1972). The effect of dust on the temperalure of the Martian atmosphere. J. Atmos. Sri. 20, 400-402.

Gitrusch, P. J., and (ioody, R. M. (1973). A model of a Martian great dust storm. $J$. Atmos. Sri. 30, $169-179$

Golitsyn, (i. S. (1973). On the Martian dust storms. Kcarus 18, 11:3-119.

HANli, R., AND Marintr 9 IRIS FXphiriment Tram (1972). Investigation of the Martian enviromment by infrared spectroscopy on Mariner 9 . Icarus 17, 423 442 .

Hrss, S. L. (1973). Martian winds and dust clouds. Planet. Space Sci. 21, 1549-1557.

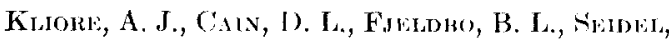
B. L., SYкK, M. J., and RAsoor, S. I. (1972). The almosphere of Mars from Mariner 9 radio ocultation ineasurements. Irarts 17, 484-516. 
Leovy, C. B., Zurek, R. W., and Pollack, J. B. Murray, B. C., Ward, W. R., and Yeung, S. C. (1973). Mechanisms for Mar's dust storms. J. (1973). Periodic insolation variations on Mars. Atmos. Sci. 30, 749-762.

Mars Engineering Model (1974). Prepared by the Viking Project Office, NASA Langley Research Center (M 75-125-3)

Masursky, H. R., and Mariner 9 TV ExperiMENT TEAM (1972). Mariner 9 television reconnaissance of Mars and its satellites: Preliminary results. Science 175, 294-305.

Mrlbourne, W. G., Mulholland, J. D., Sjogren, W. L., AND Sturms, F. M. (1968). Constants and related information for astrodynamies calculations. JPL Technical Report 32-1306.

Science 180, 638-640.

Nkwburn, R. L., ANd Gulkis, S. (1973). A survey of the outer planets Jupiter, Saturn, Uranus, Neptune, Pluto and their satellites. Space Sci. Rev. 14, 179-271.

WARD, W. R. (1974). Climatic variations on Mars. I. Astronomical theory of insolation. J. Geophys. Res. 79, 3375-3386.

Williams, G. P., and Robinson, J. B. (1973). Dynamics of a convectively unstable atmosphere: Jupiter? J. Atmos. Sci. 30, 684-717 